Résumés des conférences et travaux

\title{
Philologie italique et latine
}

\section{Dominique Briquel}

\section{OpenEdition \\ Journals}

\section{Édition électronique}

URL : https://journals.openedition.org/ashp/217

DOI : 10.4000/ashp.217

ISSN : 1969-6310

\section{Éditeur}

Publications de l'École Pratique des Hautes Études

\section{Édition imprimée}

Date de publication : 1 octobre 2008

Pagination : 94-95

ISSN : 0766-0677

\section{Référence électronique}

Dominique Briquel, «Philologie italique et latine », Annuaire de l'École pratique des hautes études (EPHE) Section des sciences historiques et philologiques [En ligne], 139 | 2008, mis en ligne le 24 novembre 2008, consulté le 12 juillet 2021. URL : http://journals.openedition.org/ashp/217 ; DOI : https://doi.org/ $10.4000 /$ ashp. 217 


\title{
PHILOLOGIE ITALIQUE ET LATINE
}

\author{
Directeur d'études : M. Dominique BriQuel, \\ correspondant de l'Institut
}

Programme de l'année 2006-2007 : I. Épigraphie étrusque et latine : étude d'inscriptions. II. Étude de textes d'historiens romains (Tite-Live, Histoire romaine, l. IX).

Les conférences de l'année 2006-2007 ont été consacrées à la continuation de l'étude du texte de Tite-Live IX, en vue de son édition dans la « Collection des universités de France », qui avait été commencée l'année précédente.

La partie du livre étudiée en 2006-2007 va du chapitre 17 au chapitre 33 et comprend donc le passage le plus célèbre de ce livre, l'excursus sur Alexandre (ch. 17-19), dans lequel l'historien padouan pose la question de ce qui serait advenu si le conquérant macédonien, après avoir vaincu l'Asie, avait tourné ses armes contre Rome - pour conclure, bien évidemment, que Rome l'aurait emporté sur celui qui passait alors pour le plus grand chef militaire de tous les temps. Les questions innombrables que soulève ce passage - réalité historique des projets occidentaux prêtés à Alexandre, utilisation de la figure d'Alexandre par une historiographie grecque hostile à Rome, rôle de l'imitatio Alexandri à Rome, signification du passage dans le débat sur les types de régimes politiques et vis-à-vis du principat, etc. - ne doivent pas faire perdre de vue la fonction qu'il occupe à l'intérieur du livre IX, comme contrepoint de la défaite des Fourches Caudines, une des plus humiliantes que Rome ait jamais connues, qui est exposée au début du livre. Le reste du livre IX est consacré à la manière dont Rome reprend le dessus après ce désastre et achève victorieusement la guerre qui l'oppose aux Samnites. La défaite est lavée dès l'année suivante par la victoire, fictive, qui est prêtée à Fabius Maximus Rullianus, lequel vainc l'armée samnite qui avait forcé les Romains à capituler, et c'est à propos de ce chef romain, qui est comparé à Alexandre, qu'est introduit l'excursus : la revanche (fictive) des Fourches Caudines est prolongée, sur un mode encore plus imaginaire, par la victoire que Rome se targue d'être capable de remporter sur n'importe quel adversaire, et pour commencer par ce modèle incontesté du chef victorieux qu'était le Macédonien.

Après ce morceau de bravoure, dont on ne peut exclure qu'il réutilise une composition qui aurait été élaborée d'une manière autonome, le livre se poursuit - avec un contraste stylistique voulu, passant brusquement à une forme beaucoup plus dépouillée - au récit de la suite des opérations, à travers lesquelles se manifeste progressivement cette suprématie de Rome. Les succès se succèdent, avec une recherche de la variété dans le traitement des épisodes. Les insuccès sont minorés, voire occultés : c'est le cas en particulier de la bataille de Lautulae en 314, qui a été une grave défaite, comme le récit parallèle de Diodore et des indices tirés du texte livien luimême permettent de le comprendre. Mais, dans la ligne de la conclusion de l'excursus sur Alexandre, l'impact de la politique intérieure n'est pas négligé : seule la concorde de la cité peut assurer à Rome cette suprématie. Or, dans cette période, Rome est 
secouée par d'abord les conséquences délétères de ce que Tite-Live présente comme une enquête policière confiée au dictateur Maenius, puis surtout, après ce premier épisode qui joue un rôle d'annonce par rapport à la crise beaucoup plus grave qui suit, celui lié à l'apparition de la figure d'Appius Claudius et sa censure de 312, qui aurait bouleversé le fonctionnement des institutions de la cité. Là encore, la présentation du personnage et de sa politique est artificielle et fausse ce qu'a dû être la réalité historique, que la thèse récente de M. Humm, Appius Claudius Caecus, la république accomplie (Rome, 2006), a cherché à retrouver derrière les partis pris de la tradition. Mais elle est intégrée dans la perspective générale du livre IX, qui, méconnaissant ce qui a été probablement le sens de l'action d'Appius, c'est-à-dire de permettre à la cité de se fonder sur la participation active, politique et militaire, d'une plus large couche de sa population, subordonne le succès de l'action de Rome à l'extérieur, lie la grandeur de Rome à la préservation d'un ordre conçu comme respectant la stricte hiérarchie des ordres. 